\title{
A method of hollowing the obturator prosthesis and an overview on the pros and cons of the various materials used for hollowing
}

\author{
Sharayu Vinod Nimonkar ${ }^{1 *}$, Vikram Murlidhar Belkhode ${ }^{1}$, Ali Mohammed Asiri ${ }^{2}$, \\ Mohammed Fawaz Aldossary ${ }^{2}$, Pranali Vinod Nimonkar ${ }^{3}$

\section{Author Affiliations:} \\ 1. Department of Prosthodontics, Sharad Pawar Dental College \& Hospital, Datta Meghe \\ Institute of Medical Sciences (Deemed to be University), Sawangi (Meghe), Wardha, \\ Maharashtra, India \\ 2. College of Dentistry, Prince Sattam Bin Abdulaziz University, Al-Kharj, Saudi Arabia \\ 3. Trauma Care Centre, Government Medical College and Hospital, Nagpur, \\ Maharashtra, India
}

\author{
* Corresponding Author: \\ Dr. Sharayu Nimonkar, MDS \\ Prosthodontics, Assistant \\ Professor, New SBI Colony \\ Nisargnagri Nagpur Road \\ Wardha 442001, India. \\ Phone: 8830977678; \\ E-mail: snimonkar@gmail.com \\ DOI \\ 10.25122/jml-2020-0142 \\ Dates \\ Received: 20 August 2020
}

Accepted: 20 November 2020

\begin{abstract}
Prosthetic rehabilitation of a partial or total maxillectomy with an obturator is the most acceptable treatment option. The hollowing of the obturator prosthesis is beneficial as it reduces the stresses over the underlying and surrounding tissues. A simple technique of fabricating a hollow bulb obturator has been discussed in this article. At the step of the packing of a denture, the hollow wax pattern of the defect area is formed with modeling wax. This hollow wax pattern is filled with water and is allowed to freeze to form an ice block. This ice block is removed from the wax pattern and is interposed between two layers for heat-cured acrylic resin and is then cured. After processing the denture, the water is retrieved by making a small hole in denture base, which is packed after hollowing with a cold cure acrylic resin. A lightweight prosthesis with a uniform thickness was achieved with a readily available and easily retrievable material, i.e., ice.
\end{abstract}

KEYWORDS: hollow bulb obturator; ice; maxillectomy.

\section{INTRODUCTION}

Maxillectomy is a term used for the removal of the partial or total maxilla in patients with benign or malignant tumors. Rehabilitating such maxillary defects with free flap surgery has shown the best results functionally as well as esthetically. Prosthetic rehabilitation is the preferred modality only when surgical intervention is not possible [1]. Patients with advanced age, poor general health, extensive defects, and poor blood supply because of radiation therapy can be considered for prosthetic rehabilitation [2].

The hard and/or soft palate defect leading to oro-nasal or oro-antral communication often leads to physical and psychological trauma to the patient. Patients planned for maxillectomy often ask about the quality of life $(\mathrm{QoL})$ that they should expect after surgery. There are many studies documented in the literature supporting a good quality of life provided by well-designed obturators prosthesis following maxillectomy [3-8].

Obturator prosthesis is a removable appliance used to close the congenital or acquired tissue opening primarily of the hard palate and/ or soft palate. This bulb of the obturator engages the defect to gain retention for the prosthesis and form a barrier for oral and nasopharyngeal communication. The bulb of the obturator prosthesis increases the weight of the prosthesis. An increase in weight hampers the retention of the prosthesis that makes the prosthesis unacceptable by the patient [9].

To avoid this, the obturator prosthesis should be made hollow. Various methods for hollowing the prosthesis with the use of different materials have been well documented in studies [10-15]. However, clinically, it has been observed that the removal of these materials from processed prostheses is a tacky job. Moreover, they could not maintain the even thickness of the hollow portion; some caused 


\section{JOURNAL of MEDICINE and LIFE}

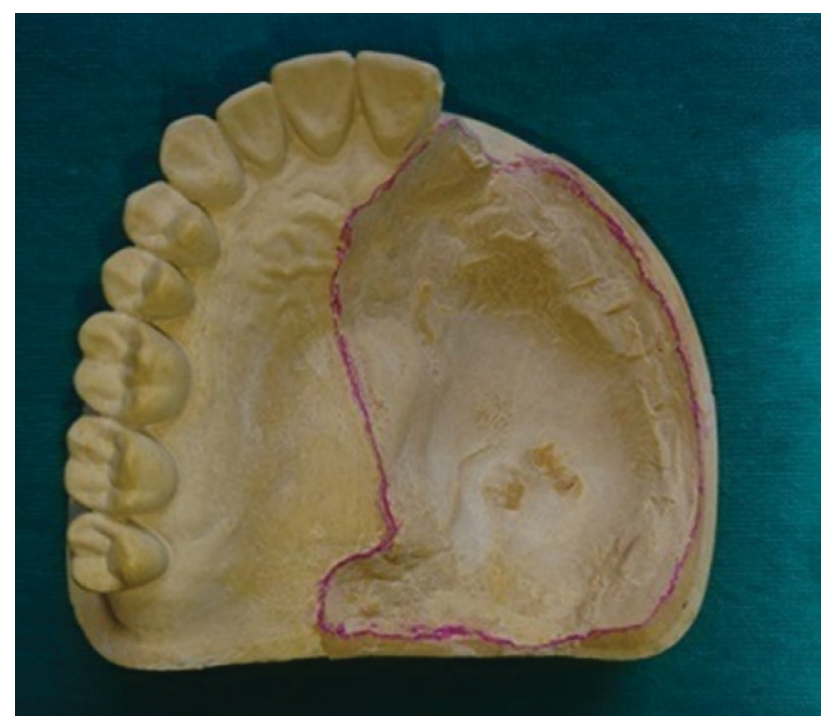

Figure 1. Maxillary cast showing the defect.

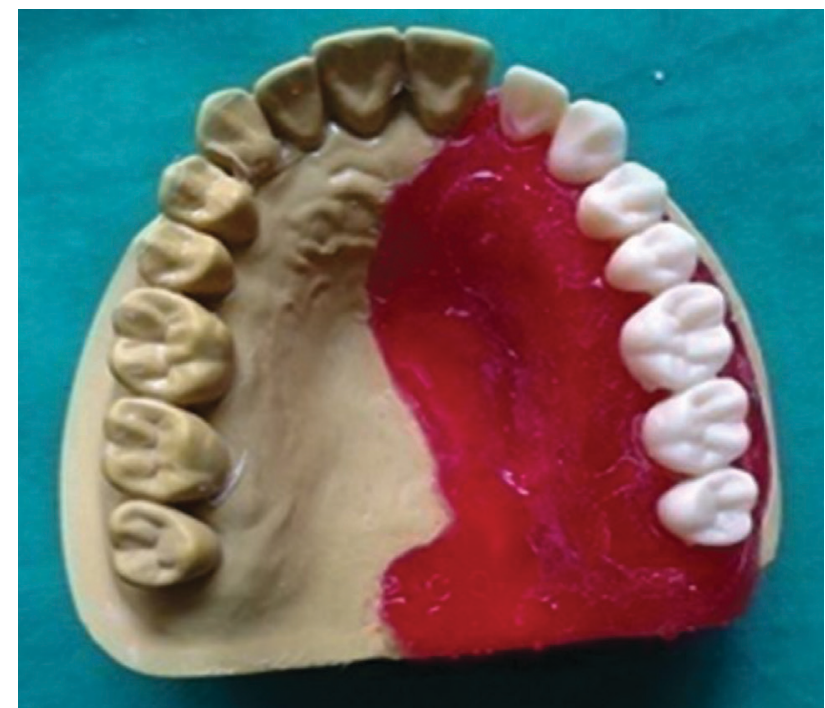

Figure 2. Trial prosthesis.

porosities, dimensional changes, and discoloration of the final prosthesis. Different techniques such as the double flask technique and use of shim of acrylic resin have been given for hollowing of the prosthesis by Fattore et al. [16] and Holt et al. [17], respectively. However, the problems faced with such techniques were an approximation of two half polymerized portions of the prosthesis and the even thickness of the prosthesis.

This article describes the technique for the fabrication of hollow obturator prosthesis using a freely accessible material, i.e., ice. A hollow wax pattern was formed by adapting modeling wax on the borders of the defect cavity. Water was filled in a hollow wax pattern to form an ice block. This ice block was placed at the time of curing as a hollowing material. After processing the denture, the ice water was retrieved by making a small hole in the denture base.

The ice block used in this method as a material for hollowing could withstand the pressure of the compression molding technique and did not cause discoloration of the denture, as seen with many materials used for hollowing. It also provided ease of retrievability. Moreover, this technique maintained the even thickness of the hollow portion and also aided in the complete curing of the bulb portion.

\section{TECHNIQUE}

All clinical and laboratory procedures for fabricating the obturator prosthesis from preliminary impression until de-waxing of the trial denture were done conventionally (Figures 1 and 2). After de-waxing (Figure 3), modeling wax (Pyrax, Pyrax Polymar, India) was softened uniformly in warm water and was adapted on the walls of the defect area on the base flask and counter flask (Figure 4). The excess wax that extended from the defect area was flamed, and the flask was closed to get a wax pattern.

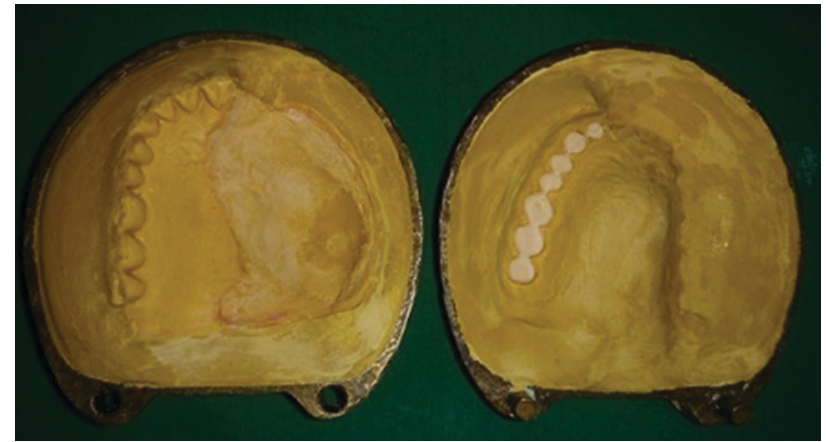

Figure 3. Dewaxed flask.

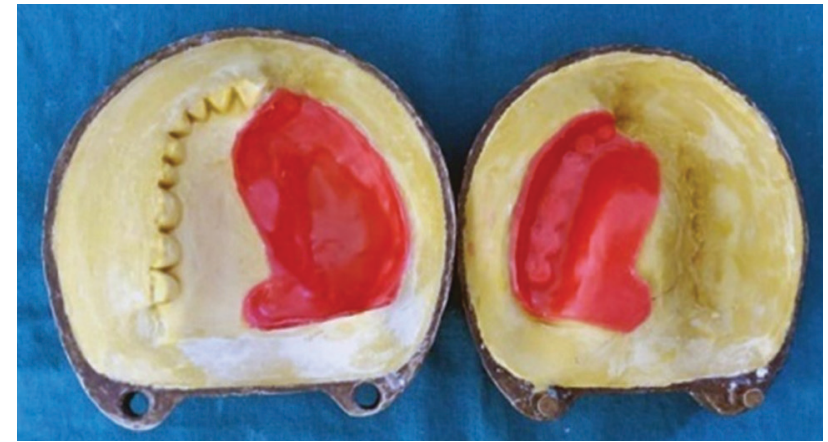

Figure 4. Wax sheet adapted on the defect area to form the wax pattern. 


\section{JOURNAL of MEDICINE and LIFE}

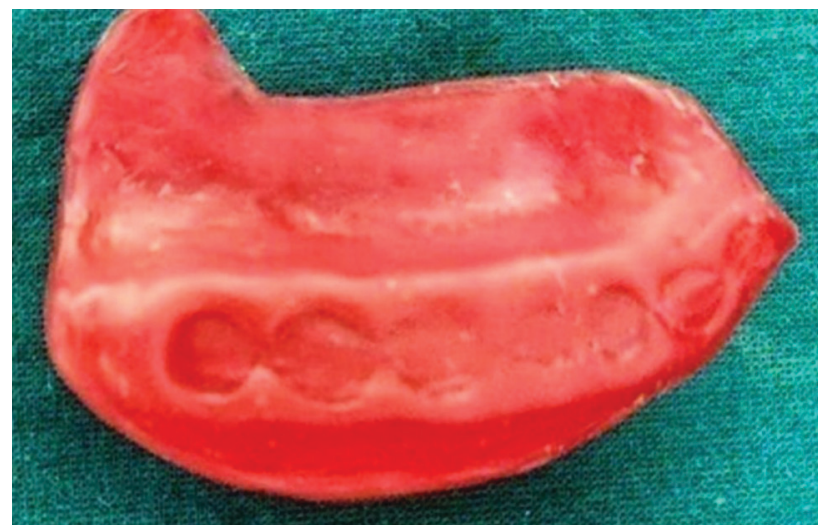

Figure 5. The wax pattern.

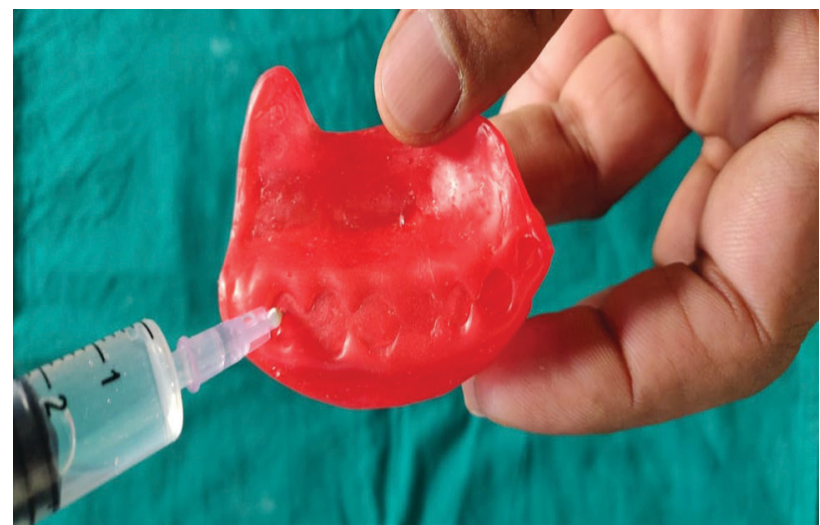

Figure 6. Injection of water into the wax pattern.

The wax pattern was removed carefully from the flask and was checked for the seal (Figure 5). Water was injected with the help of a syringe in the wax pattern (Figure 6). The wax pattern, along with water in it, was kept in the freezer for $24 \mathrm{hrs}$ to form ice.

After setting the ice, the wax pattern was removed to get the ice block. (Figure 7). The heat cure acrylic resin (DPI) was mixed in dough consistency as per the manufacturer's instruction and was placed in a base and counter flask with an ice block interposed between them in the defect area (Figure 8). The mold was closed and clamped. The clamped mold was then immediately placed in an acrylizer without bench curing and was cured with a short curing cycle for 90 min at $74^{\circ} \mathrm{C}$ followed by boiling at $100^{\circ} \mathrm{C}$ for 60 minutes.

Once the curing was complete, the flask was allowed to bench cool for an hour. Then, it was opened, and the prosthesis was retrieved. A small hole was drilled in the prosthesis for the retrieval of water to make it hollow. Water effortlessly came out of the prosthesis, and then the hole was closed with the self-cure acrylic resin (DPI).

The obturator prosthesis was weighted before and after hollowing (Figures 9 and 10). Uniformity in the prosthesis thickness was achieved and measured with the help of a vernier caliper (Figure 11).

\section{DISCUSSION}

While restoring a large defect, reducing the weight of the prosthesis by making it hollow is beneficial, especially for obturator prosthesis, wherein the heavyweight of the acrylic resin threatens the retention, stability, and support of the prosthesis, making the patient feel

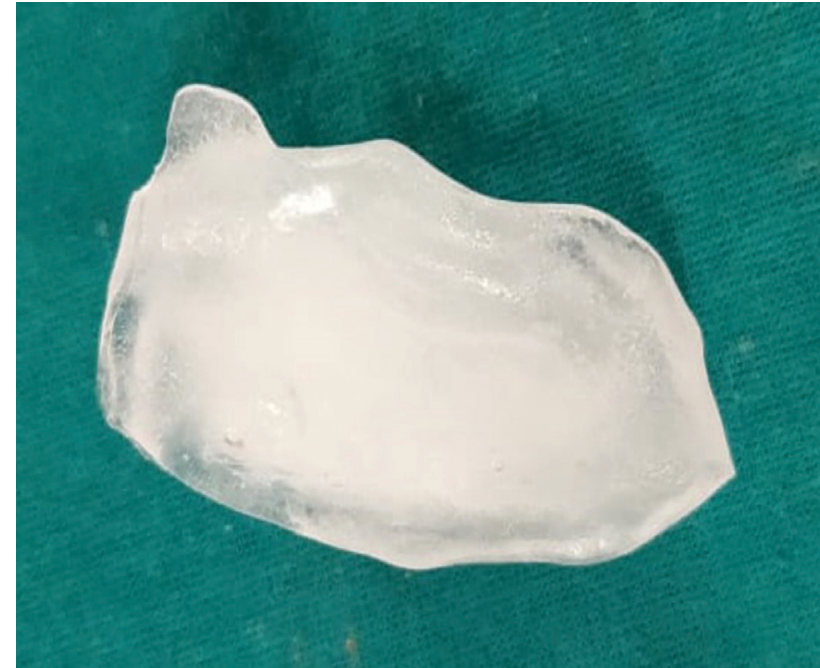

Figure 7. Ice block retrieved from the wax pattern.

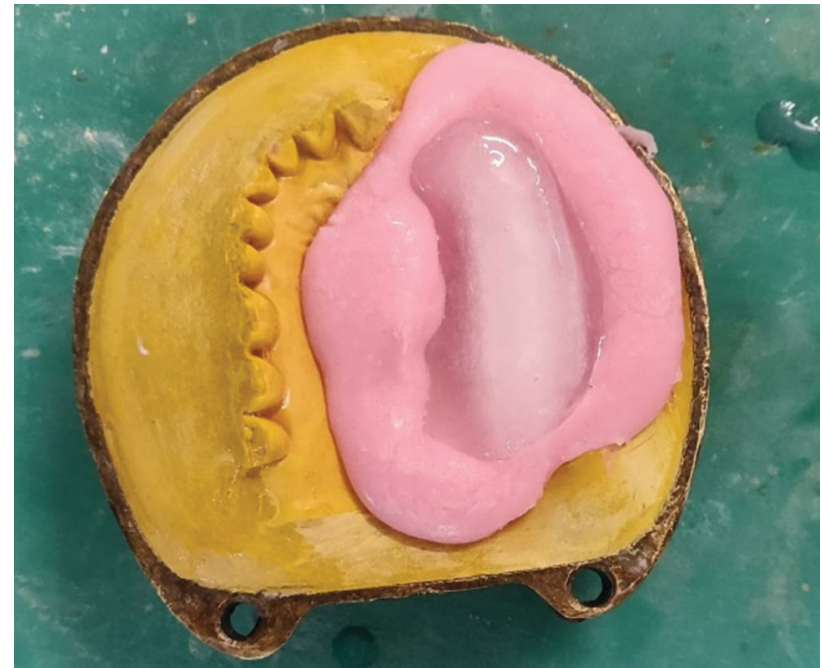

Figure 8. Ice block positioned on the base flask at the time of packing. 


\section{JOURNAL of MEDICINE and LIFE}

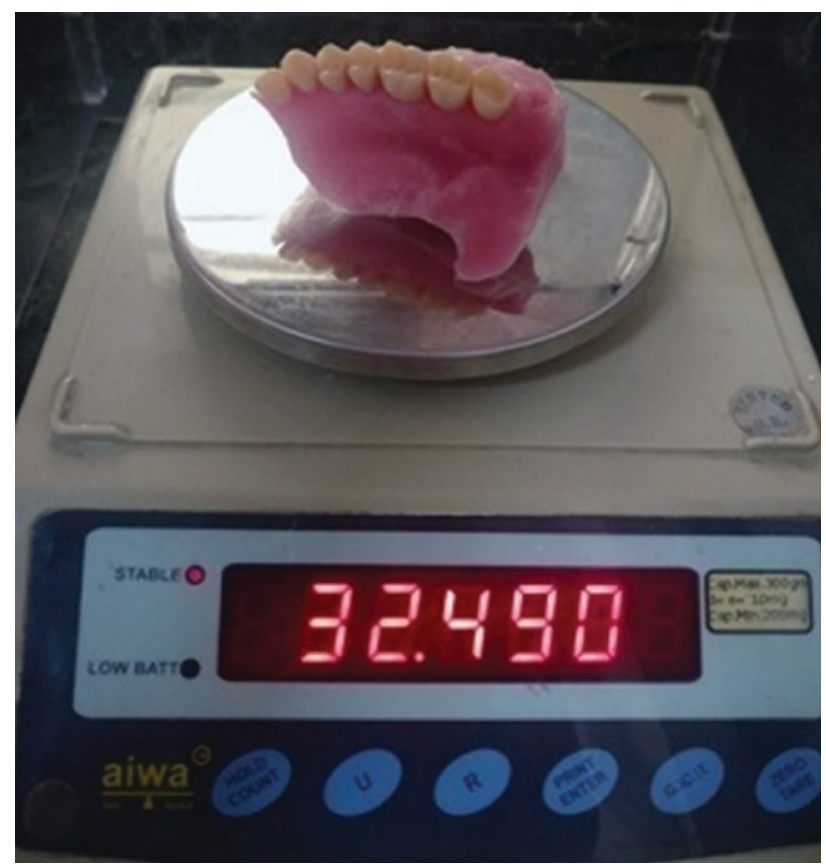

Figure 9. Weight of the prosthesis before hollowing of the prosthesis

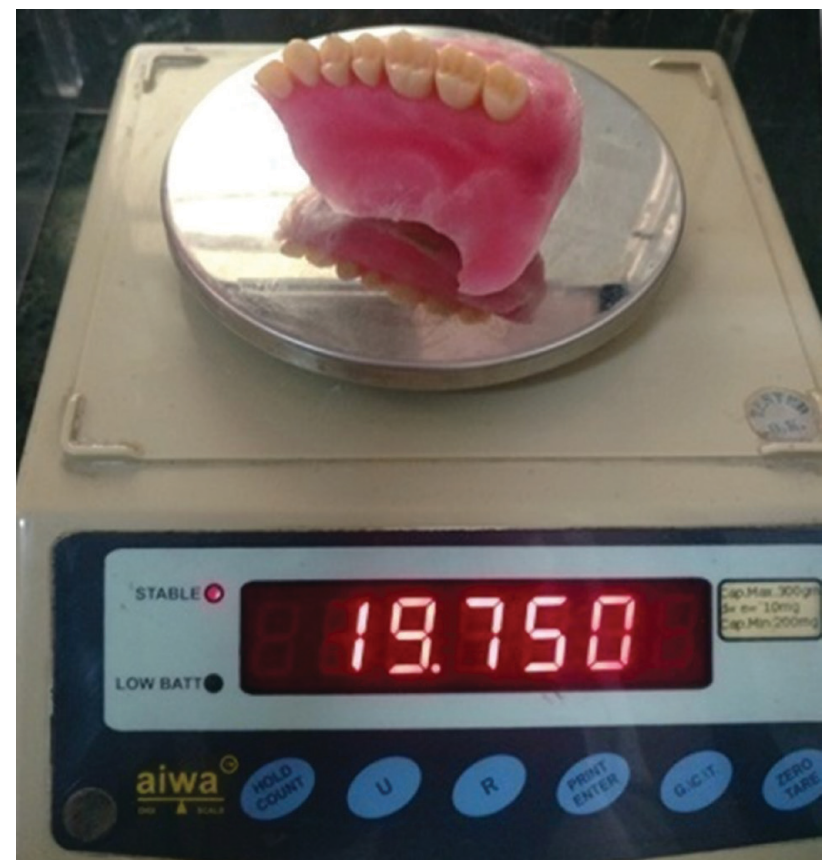

Figure 10. Weight of the prosthesis after prosthesis hollowing.

uncomfortable. Moreover, the heavyweight of the prosthesis increases the stress over the residual alveolar ridge and supporting bone that leads to further resorption of the denture-bearing foundation [18].

Several techniques and materials for the hollowing of the obturator prosthesis have been described in the literature to fabricate a lightweight prosthesis [10-16]. Materials such as silicon [19], a slurry of plaster and pumice [20], gelatin [21], modeling clay [22], cellophane wrapped in asbestos [23], salt [24], polyurethane foam [25], acrylic resin shim [26], have been used for hollowing the prosthesis. However, these materials encountered problems during removal after processing through the small holes drilled in the prosthesis resulting in the heavyweight prosthesis. Moreover, some materials were costly and could not maintain the even thickness of the hollow portion, could not withstand the compression molding pressure, and could not sustains the curing temperature. Some materials increased the risk of seepage and discolored the prosthesis. Some material reacted with heat-cured acrylic resin resulting in porosities that affected the mechanical properties (Table 1). This article described a simple, unique, and less time-consuming technique to fabricate a hollow obturator prosthesis using ice.

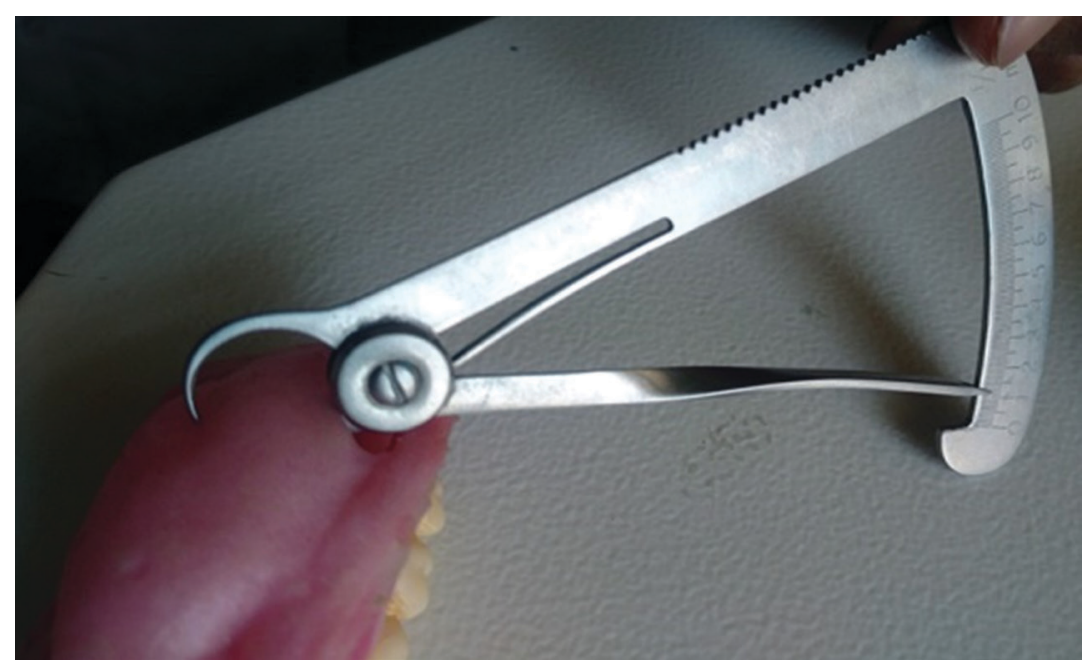

Figure 11. Uniform thickness of the prosthesis measured using a vernier caliper.
In 1978, Schneider et al. also used ice to hollow the obturator prosthesis. The authors advocated for the use of crushed ice in the defect area for hollowing. However, crushed ice can not completely fill the defect space and will result in uneven thickness of the hollow bulb, resulting in a further increase in the weight of the prosthesis [27]. To overcome this problem, the technique of using an ice block to precisely occupy the defect area and to achieve even thickness of the obturator prosthesis was developed.

The prosthesis weighed 32.49 grams before and 19.75 grams $t$ after retrieval of water. A reduction of 12.74 grams of weight after retrieval of water is remarkable, which is achieved by the hollowing of the prosthesis. The uniform thickness of the prosthesis, of 


\section{JOURNAL of MEDICINE and LIFE}

around $1.3 \mathrm{~mm}$, was measured with a vernier caliper. Hollowing the prosthesis affects the flexural strength. If the clinician is more concerned about reducing the weight of the prosthesis, then the strength will be compromised, affecting the mechanical properties of the material [28].

When the boiling process is held in the pressure vessel, the water starts to boil at a higher temperature than $100^{\circ} \mathrm{C}$. At a certain point, the energy absorbed by the water molecules makes them vibrate fast, and it attempts to escape and evaporate. However, the atmosphere around them exerts pressure on and thus limits the number of water molecules that can escape. Therefore, a minimal volume of water will expand, but the closed flask will limit it and not affect the accuracy of the obturator prosthesis.

\section{Table 1. Pros and cons of various hollowing materials.}

\begin{tabular}{|c|c|c|c|}
\hline Sr.No & $\begin{array}{l}\text { Material used for } \\
\text { hollowing }\end{array}$ & Pros & Cons \\
\hline 1 & Wax shim & - Ease of retrievability & $\begin{array}{l}\text { - The difficulty of reliably seating wax-bolus in polymerizing resin } \\
\text { during packing } \\
\text { - Uniformity of resin thickness is difficult to achieve } \\
\text { - Chances for dimensional change in the wax-bolus resulting from } \\
\text { curing temperature } \\
\text { - Time-consuming } \\
\text { - Technique sensitive } \\
\text { - Discoloration of final prosthesis occurs due to wax. }\end{array}$ \\
\hline 2 & Sugar & $\begin{array}{l}\text { - Highly soluble } \\
\text { - Ease of removal } \\
\text { - } \text { Moldable }\end{array}$ & $\begin{array}{l}\text { - Roughness is observed on the hollow surface } \\
\text { - Chance to break during compression molding } \\
\text { - Strength is affected by porosities } \\
\text { - Brittle }\end{array}$ \\
\hline
\end{tabular}

3

Acrylic resin
shim

5 Polyurethane foam

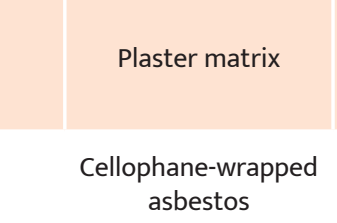

8

Silicone putty

9 Light-body coated
gauze

- Simple technique

\section{0}

Thermocol

- Simple to execute
- It leaves no lines of demarcation to discolor the denture

- The technique is easy to carry out

- Recontoured easily

- It sustains curing temperatures

- Maintains the uniform thickness

- Maintains the uniform thickness

- No difficulty in gauging resin thickness

- Does not adhere to acrylic resin - Ease of gauging resin
thickness
- Time-consuming

- Technique sensitive

- Complex

- Time-consuming

- Difficult to remove after curing

- The even thickness of the hollow portion is difficult to maintain

- Chance to break during compression molding

- Complex

- Time-consuming

- Brittle

- Allergy to asbestos

- Difficult to remove

- Difficult to remove

- Time-consuming

- Difficult to remove

- Difficulty in gauging resin thickness

- Compromises the strength of the prosthesis

- Gauging resin thickness is difficult

- Left in the denture so no complete hollowing is achieved

- Get displaced during compression molding

- Complex

- Time-consuming

- Difficult to remove

- Complex

- Time-consuming

- Difficult to remove 


\section{JOURNAL of MEDICINE and LIFE}

\begin{tabular}{|c|c|c|c|}
\hline 13 & Salt & $\begin{array}{l}\text { - } \text { Simple technique } \\
\text { - } \text { Cost effective } \\
\text { - No residual crystals left } \\
\text { after curing }\end{array}$ & $\begin{array}{l}\text { - } \text { Brittle } \\
\text { - } \text { Chance to break during compression molding } \\
\text { - Salt may react with heat cured acrylic resin and may lead to } \\
\text { porosity }\end{array}$ \\
\hline 14 & Gelatin soap & $\begin{array}{l}\text { - } \text { Recontoured easily } \\
\text { - It sustains curing } \\
\text { temperatures } \\
\text { - Easy retrievability }\end{array}$ & $\begin{array}{l}\text { Retrieval is done with hot water sprayed through the opening } \\
\text { using a disposable syringe, resulting in the possibility of } \\
\text { incomplete gelatin removal } \\
\text { - Junction is formed between the two previously polymerized } \\
\text { portions of the denture which may be at an increased risk of fluid } \\
\text { seepage into the denture cavity. }\end{array}$ \\
\hline 15 & Alum & - Ease of retrieval & $\begin{array}{l}\text { - Leaving cellophane in the prosthesis } \\
\text { - Difficulty in shaping the alum crystals to the defect }\end{array}$ \\
\hline
\end{tabular}

\section{Pros of the present technique}

- $\quad$ Ease of retrievability;

- Maintains even thickness of the hollow portion;

- Ice does not adhere to acrylic resin;

- The ice block can withstand the pressure of compression molding technique;

- Ice does not create porosities, so it does not compromise the strength of the prosthesis;

- $\quad$ Ice leaves no lines of demarcation to discolor the denture;

- Ice aids in the complete curing of the bulb portion;

- Total removal of ice is possible so complete hollowing of a prosthesis can be achieved;

- The procedure is not technique sensitive;

- $\quad$ Ease of availability;

- Inexpensive.

\section{Limitations of the present technique}

- The flexural strength of the hollowed structure was not determined.

Other prostheses such as finger prosthesis, vaginal stent, complete dentures for severely atrophic ridges, and prosthesis for mandibular resection can also make use of ice to make them hollow. Future studies are suggested to evaluate the changes in the properties of the heat cure acrylic resin after processing with this technique. An experimental test program is recommended using numerical modeling as a tool to predict the behavior of the hollowed structure in terms of its mechanical properties [29]. Also, there is a need to perform uncertainty analysis with a sensitivity analysis toolbox consisting of Matlab functions that offer utilities for quantifying the influence of uncertain input parameters on uncertain model outputs [30].

\section{CONCLUSION}

An alternative, simple, economical, time-saving, and predictable approach for the hollowing of the prosthesis has been described in this article. This technique overcomes the disadvantages of the older techniques. The ice block has the advantage of retrievability ease, and it does not adhere to acrylic resin. It also provides an even thickness of acrylic resin during the packing stage and resists deformation during the closure of the mold.

\section{ACKNOWLEDGMENTS}

\section{Conflict of interest}

The authors declare that there is no conflict of interest. 


\section{JOURNAL of MEDICINE and LIFE}

\section{REFERENCES}

1. Lethaus B, Lie N, de Beer F, Kessler P, de Baat C, Verdonck HW. Surgical and prosthetic reconsiderations in patients with maxillectomy. J Oral Rehabil. 2010;37(2):138-42.

2. Nimonkar SV, Belkhode VM, Sathe S, Borle A. Prosthetic Rehabilitation for Hemimaxillectomy. J Datta Meghe Inst Med Sci Univ. 2019;14:99-102.

3. Belkhode VM, Nimonkar SV, Chaudhary SC, Hakkepatil Anuja, Nimonkar P, Prajapat J. An Innovative Method for Iris Positioning in a Prosthetic Eye. J Contemp Dent Pract. 2020;21(7):815-818

4. Dudhekar A, Nimonkar SV, Belkhode VM, Borle Anjali, Bhola R. Enhancing the Esthetics with All Ceramic Prosthesi J Datta Meghe Inst Med Sci Univ

2018; 13(3):155-157.

5. Sathe S, Pisulkar S, Nimonkar SV, Belkhode VM, Borle A, Positioning of iris in an ocular prosthesis: A systematic review. J Indian Prosthodont Soc. 2020;20(4):345-352.

6. Belkhode VM, Nimonkar SV, Agarwal Aashika, Godbole SR, Sathe Seema. Prosthodontic Rehabilitation of Patient with Mandibular Resection using Overlay Prosthesis: A Case Report. J Clin Diagn Res. 2019 ;13(2): ZD10-ZD13.

7. Artopoulou II, Karademas EC, Papadogeorgakis N, Papathanasiou I, Polyzois G. Effects of sociodemographic, treatment variables, and medical characteristics on quality of life of patients with maxillectomy restored with obturator prostheses. J Prosthet Dent. 2017;1 18(6):783-789.e4.

8. Nimonkar SV, Sathe S, Belkhode VM, Pisulkar S, Godbole S, Nimonkar PV. Assessment of the Change in Color of Maxillofacial Silicone after Curing Using a Mobile Phone Colorimeter Application. J Contemp Dent Pract. 2020;21(4):458-462.

9. Gundawar S, Zamad A, Gundawar S. Light weight dentures: An innovative technique. Contemp Clin Dent. 2014;5(1):134-137.

10. Gandhi N, Talwar H, Gandhi S, Alageshan V, Abraham G, Mehdiratta S. Prosthodontic rehabilitation of a sub-total maxillectomy defect with a definitive hollow obturator prosthesis using the modified lost-wax concept: A novel technique. Natl J Maxillofac Surg. 2018;9(2):225-228.

11. Kaira LS. Maxillary hollow denture: A case series. Journal of Orofacial Research. 2012;2(18):109-112

12. Punjabi AR, Mistry G, Shetty O, Rathod A. Maxillary hollow-bulb obturator: A paradigm shift. J Indian Prosthodont Soc. 2019;19(1):74-78.

13. Caculo SP, Aras MA, Chitre V. Hollow dentures: treatment option for atrophic ridges. a clinical report. J Prosthodont. 2013;22(3):217-222.

14. Asher ES, Psillakis JJ, Piro JD, Wright RF. Technique for quick conversion of an obturator into a hollow bulb. J Prosthet Dent. 2001;85(4):419-420.

15. Deogade SC, Patel A, Mantri SS. An alternative technique for hollowing maxillary complete denture. J Indian Prosthodont Soc. 2016;16(4):412-415.

16. Fattore LD, Fine L, Edmonds DC. The hollow denture: an alternative treatment for atrophic maxillae. J Prosthet Dent. 1988;59(4):514-516.

17. Holt RA Jr. A hollow complete lower denture. J Prosthet Dent. 1981;45(4):452-454.

18. Hori K, Miyamoto T, Ono T, Yamamoto M, Shiroshita $\mathrm{N}$, Maeda Y. Inoue M. One step polvmerizing technique for fabricating a hollow obturator. J Prosthodont Res. 2013;57(4):294-297.

19. Gardner LK, Parr GR, Rahn AO. Simplified technique for the fabrication of a hollow obturator prosthesis using vinyl polysiloxane. J Prosthet Dent. 1991;66(1):60-62.

20. Nidiffer TJ, Shipman TH. Hollow bulb obturator for acquired palatal openings. J Prosthet Dent. 1957;7(1):126-134.

21. Jhanji A, Stevens ST. Fabrication of one-piece hollow obturators. J Prosthet Dent. 1991;66(1):136-138.

22. DaBreo EL. A light-cured interim obturator prosthesis. A clinical report. J Prosthet Dent. 1990;63(4):371-3.
23. O'Sullivan M, Hansen N, Cronin RJ, Cagna DR. The hollow maxillary complete denture: a modified technique. J Prosthet Dent. 2004:91(6):591-594.

24. Aggarwal H, Jurel SK, Singh RD, Chand P, Kumar P Lost salt technique for severely resorbed alveolar ridges: An innovative approach. Contemp Clin Dent. 2012;3(3):352-355.

25. Tanaka Y, Gold HO, Pruzansky S. A simplified technique for fabricating a lightweight obturator. J Prosthet Dent. 1977;38(6):638-642

26. Chalian VA, Barnett MO. A new technique for constructing a one-piece hollow obturator after partial maxillectomy. J Prosthet Dent. 1972;28(4):448-453.

27. Schneider A. Method of fabricating a hollow obturator J Prosthet Dent. 1978;40(3):351.

28. Yadav NS, Narwani S, Hazari P, Mishra SK, Somkuwa S, Bhatia R. Comparison of flexural strength of different techniques for fabrication of hollow dentures - an in vitro study. University J Dent Scie. 2016;2(2): 1-4.

29. Hamdia KM, Marino M, Zhuang X, Wriggers P, Rabczuk T. Sensitivity analysis for the mechanics of tendons and ligaments: Investigation on the effects of collagen structural properties via a multiscale modeling approach. Int J Numer Methods Biomed Eng. 2019;35(8):e3209.

30. Vu-Bac N,, Lahmer T, Zhuang X, Nguyen-Thoi T, Rabczuk T. A software framework for probabilistic sensitivity analysis for computationally expensive models. Adv Eng Softw.2016;100:19-31. 